\title{
Antônio Ferreira de Almeida Júnior
}

Professor catedrático de Medicina Legal

O dr. Antônio Ferreira de Almeida Júnior nasceu em Joanópolis, Estado de São Paulo, a 8 de junho de 1892, sendo seus páis o sr. Antônio Ferreira de Almeida e d. Otília Caparica de Almeida (já falecida). Feitos, na sua terra natal e em São Paulo, os estudos primários e preparatórios, matriculou-se, em 1906, na Escola Normal da Praça da República, pela qual se diplomou em 1909, depois de haver alcançado os prêmios "Pereira Barreto" (Física e Química) e "Rio Branco" (História do Brasil). Em 1915, concluiu os exames de curso secundário perante o Ginásio do Estado, matriculando-se, no ano seguinte, na Faculdade de Medicina desta capital. Aí se doutorou em 1921, tendo sido, na defesa da tese, aprovado com grande distinção.

Em sua atividade docente, o professor Almeida Júnion tem exercido, contemporaneamente, o magistério público e o particular.

No magistério público, começando como professor primário, em Santos e depois na Capital (1910), lecionou, sucessivamente, na antiga Escola Complementar de São Paulo (1910), na Escola Normal de Pirassununga (1911 a 1915) e no Instituto Disciplinar (1915 a 1919). Em 1920, foi chamado pelo professor SAMPálo DóRIA, então diretor geral do Ensino, para seu auxiliar, sendo, em 1921, nomeado professor de Biologia e Higiene da Escola Normal do Braz. Transferido, em 1930, para o curso de aperfeiçoamento do Instituto de Educação, tornou-se, em 1933, professor de Biologia educacional dêsse estabelecimento (o qual, no ano seguinte, se incorporou à Universidade de São Pau- 
lo). Extinto, em 1938, o Instituto de Educação, foi o professor Almeida Júnion, como todos os seus colegas, transferido para a Faculdade de Filosofia, Ciências e Letras, - secção de Educação —, da qual passou agora para a cadeira de Medicina Legal da Faculdade de Direito, em que, aliás, já era livre docente desde 1928, tendo estado, a partir desta data, quase sempre na regência da cadeira.

O professor Almeida Júnior fez parte da comissão de doze professores, a qual organizou o ante-projeto, transformado na lei de 25 de janeiro de 1934, que instituiu a Universidade de São Paulo. Membro do primeiro Conselho Universitário, como representante do Instituto de Educação compôs, com os professores A. de Sampáio Dória e Teodoro Ramos, a comissão encarregada de organizar os Estatutos da Universidade; e, aprovados estes, integrou a comissão que redigiu o regimento interno da mesma Universidade.

No magistério particular, colaborou na fundação do Liceu Rio Branco, de que foi diretor e professor desde 1926 até 1934. E' igualmente um dos fundadores da Escola Paulista de Medicina, a cujo corpo docente pertence, como professor de Mredicina Legal. Inaugurou, por fim, entre nós, na Escola de Sociologia e Política, em que é membro do Conselho Diretor, o ensino de Fisiologia e Higiene do Trabalho.

De 1921 a 1923, fez parte do Instituto de Higiene, como assistente pensionado. Na administração pública, exerceu os cargos de chefe do Serviço Médico-Escolar (1933) e de diretor geral do Ensino (1935-1938). Riepresentou o Estado de São Paulo em diferentes congressos: $10^{\circ}$ Congresso Brasileiro de Higiene (Rio, 1923), Congresso de Proteção à Criança (Rio, 1933), Congresso de Educação (Ceará, 1934), Congresso de Ensino Regional (Baía, 1935), Congresso de Educação Física e Estatística (Rio, 1936). É consultor técnico do Instituto Nacional de Estatística (secção de Biologia) e membro do Conselho Médico-Legal do Estado.

Classificado em primeiro logar, por unanimidade, pela Comissão Examinadora cujo parecer obteve, por parte da 
Congregação, aprovação tambem unânime, o professor ALMEIDA JÚNIOR foi nomeado para reger a cadeira de Medicina Legal por decreto de 3 de dezembro de 1940. A posse efetuou-se a 10 do mesmo mês, em sessão solene da Congregação, na sala "João Mendes Júnior", sob a presidência do diretor da Faculdade, professor J. J. Cardozo de Melo Neto. Uma comissão constituida dos professores Francisco Morato, Vicente Ráo e Miguel Reale introduziu no recinto o novo catedrático, o qual, depois do compromisso da lei, foi saudado pelo diretor com as seguintes palavras:

"Esta solenidade é tradicionalmente uma saudação cordial e um voto de esperança.

A saudação ao novo professor que, após duras provas de sua cultura e aptidão, toma definitivo assento neste doutoral.

Um voto de esperança por que esteja sempre à altura de sua responsabilidade quem, com tanto desprendimento das riquezas terrenas, se reveste espontaneamente de tâo alta dignidade pública.

Hoje, diante de vós, sr. professor Almeida Júnior, mantém-se íntegra a fórma legal da investidura, mas a saudação e $o$ voto têm sentido peculiar.

Não é a simples saudação cordial ao recipiendário. E' o abraço fraternal de cada um de vossos colegas 'que, ha mais de doze anos, vos consideram como um dos nossos, de maior capacidade afetiva, de maior compreensão dos deveres que a nossa tradição sublima. E' o abraço filial de todos os vossos discipulos, os de hoje como os de ontem, entre os quais alguns jả se encontram entre os membros desta Congregação.

$E$, acima de tudo, não é um voto de esperança. E' a afirmação de uma realidade. Da realidade vitoriosa que é a vossa vida, iniciada e integralmente vivida dentro do magistério, orientada exclusivamente na educação da mocidade, pela palavra, que em vós é um encanto de claridade e ordenado saber, pela ação desprendida e modesta, que em vós é quasi um defeito. 
Recebeis em definitivo a cadeira de Medicina Legal. Dois foram seus ocupantes: Amâncio dE CarvalHo que a inaugurou e à qual, durante quarenta anos, deu todo seu sadio entusiasmo e sua invulgar capacidade de transmitir; e Alcântara Machado que por ela passou como um ráio de luz, como foi sua vida. Dois temperamentos dispares, irmanados na dedicação a esta Academia que para ambos foi a própria razão de existir.

Sois bem o legítimo herdeiro de tão invulgar herança. Conservai-a, acrescendo-a.

Eis o sentido da nossa saudação, e do nosso voto".

Falou, a seguir, em nome da Faculdade de Filosofia, Ciências e Letras, o professor Mrlton da Silva Rodrigues, que assim se expressou:

"Se a sêde de conhecer aquilo que nos cerca, muito mais que a um imperativo da necessidade, obedece por certo a um verdadeiro instinto que à própria criança não é estranho, sob a fórma de ingênua curiosidade, constitue ela, porém, de começo, mera fase rudimentar e primária, destinada antes a suscitar problemas sempre novos, do que a resolver aqueles primeiros que nos despertaram o espírito.

À simples busca, ainda que exaustiva, de noções, seguese muito naturalmente o desejo, ou melhor, a necessidade lógica de lhes pôr ordem, organizando-as em sistema à custa de um princípio de unidade. E assim, desde que o homem pela vez primeira, ao que sabe a História, voltou os olhos para o mundo que o circunda, não deixou jamais de apresentar os resultados das suas indagações, por mais singelas e primitivas que fossem, senão já coordenadas e unidas num todo, por vezes de infantil simplicidade. E foi assim que, de um modo ou de outro, ele sempre teve à mão, para tranquilidade do seu espírito e orientação dos seus atos, uma "imagem do mundo", um panorama das coisas.

Frequentemente se deslocou o ponto-de-vista desse panorama; vezes inúmeras se lhe alterou o estilo da pintura. Mas, para cada época e logar, não constituia ele tão só o 
guia e confortador das conciências individuais, como ainda o liame principal das pessoas reunidas em grupos; e, por isso mesmo, os momentos de transição, quando, perdida a fé numa estrutura antes aceita, as opiniões ainda se dividiam inquietas, à cata de um novo princípio de unidade, esses instantes, digo, corresponderam a graves crises de pensamento e da sociedade.

Aqueles que, na idade-média, reunindo-se espontaneamente, deram vida às primeiras universidades, submetendo as sete artes liberais ao ceptro da Teologia, foram, talvez, os primeiros, tambem, a colocar explicitamente a finalidade suprema dos estudos superiores: a de construir os conhecimentos humanos como um todo único e convergente. A unidade dos conhecimentos, com o seu inevitavel corolário, a sua universalidade, constituiram assim a essência espiritual do "studium generale" Unidade lógica, unicidade no tempo e no espaço, eram o bastante para fazer dele o esteio da tradição e da paz, o baluarte de resistência às crises espirituais e políticas.

Visão certamente por demais estática, o que nela havia de verdadeiro e bom foi felizmente preservado. Não mais se contenta o homem com impor às coisas um princípio transcendente de unidade, que ele intue ou se lhe revela, mas que por vezes vem a dar numa abreviação inoportuna que, fornecendo prematuramente uma explicação total, sacia a curiosidade; no entanto, só a insatisfação é realmente criadora.

Por isso, o espírito universitário atual se continua fiel ao princípio da unidade e da universalidade da ciência, juntou-lhe, desde começos do século passado, o da pesquisa livre e sistemática. Isto emprestou à universidade, além do fim que já tinha de manter as ligações com o passado, aquele de preparar o futuro, como produto deliberado da evolução do primeiro, o que certamente é maneira mais apta de se opôr às crises. E esta nova crença num princípio de unidade imanente às cousas, que é preciso construir penosamente, através dos instrumentos de indagação científica especializa- 
da, em absoluto não se opõe à da fé antiga numa ordem transcendente que, mesmo por ser assim, a tudo tem que informar e em tudo refletir-se.

Se em tais considerações eu me atardei, senhor professor Almeida Júnion, foi justamente por ver em vós uma das personalizações mais completas desse espírito característico do verdadeiro universitário: o daquele que através da pesquisa, meticulosa e paciente, constrói capítulos da ciência, como partes de um mesmo todo, que é patrimônio comum da humanidade de todos os tempos. Não o afirmo presumindo apenas das já significativas premissas dos vossos títulos de médico, professor da Faculdade de Filosofia e antigo administrador do ensino, por isso que de vós aí temos obras escritas, tais como "Paternidade" ou "A Embriaguez no Teatro de Shakespeare" que bem demonstram aquele sentido de unidade e humanidade brotando da pesquisa desprevenida e rigorosa; e está diante de nós a obra não escrita e, sem embargo, mais notavel ainda e digna de admiração, que é a vida exemplar de educador a que vos dedicastes por inteiro e em que culminaram vossas qualidades, já didáticas, na docência, já de equilíbrio e elevação de vistas, na administração do ensino público.

Quando o. Conselho Técnico-Administrativo e a Congregação da Faculdade de Filosofia, Ciências e Letras resolveram enviar à cerimônia de vossa posse uma comissão de representantes seus e solicitar do exmo. sr. Diretor da Faculdade de Direito vênia para apresentar-vos suas calorosas saudações, não o fez sómente por tratar-se de um membro daquela Congregação e sentir-se ela sumamente honrada e jubilosa com a vossa vitória. Fê-lo tambem por ver em vós a expressão viva do espírito cuja disseminação e defesa constituem a própria razão de ser da Faculdade de Filosofia. E se fui o escolhido para trazer-vos estas palavras de despedida e felicitação, foi unicamente na esperança de que elas, perdendo embora no seu brilho e expressividade, pudessem ganhar, no entanto, no colorido que lhes desejaria 
saber dar alguem que goza do privilégio de vossa amizade e, através dos bons e dos maus momentos em que a luta pelos mesmos ideais os reuniu, aprendeu a estimar em vós, sôbre as vossas qualidades de espírito e de cultura, as do vosso carater retilíneo, sereno e bom.

Que a felicidade que bem mereceis vos acompanhe em vosso novo cargo, é o voto ardente e sincero que faz neste momento a Faculdade de Filosofia; que o triunfo continuará galardoando os vossos esforços, é a sua certeza".

Agradecendo, falou, por fim, o novo catedrático de Medicina Legal:

"Meus senhores:

Ao assumir, neste momento culminante de minha carreira didática, a cátedra de Medicina Legal da Faculdade de Direito da Universidade de São Paulo, que o meu primeiro pensamento se volva, em reverente tributo de admiração, para a memória dos dois grandes mestres que me precederam.

Quasi não conheci Antônio Amâncio Pereira de CarvaLHo, e uma únică vez pude falar-lhe, visitando-o meses antes de sua morte. Mas a quem pretenda celebrar-lhe as altas qualidades de mestre, bastará procurar inspiração na carinhosa reminiscência que dele guardam os seus discípulos, alguns dos quais têm hoje assento nesta douta Congregação. Fundador que foi, em nossa Faculdade, do ensino de Medicina Pública, a ele consagrou trinta e três anos de ação infatigavel, só consentindo em abandonar o posto quando o cansaço e a doença o abateram. Ao apreciar-lhe os méritos, Valdemar Ferreira, usualmente parco em elogios, escreveu esta frase singela e lapidar: "Professor assíduo, devotadíssimo ao magistério, claro nas lições, conseguiu converter os seus alunos em amigos, pelo afeto que lhes dispensava". Se ha, meus senhores, uma parcela de glória na modéstia do cumprimento do dever, sem espetáculo nem ruido, sem outra ambição que não seja a de servir, essa parcela a alcançou 
Amâncio de Carvalho, cujo nome venerando, pronunciado com respeito por mais de trinta gerações acadêmicas, vai em breve gravar-se no pórtico da sala privativa de Medicina Legal desta Faculdade.

José de Alcântara Machado de Oliveira, professor substituto desde 1895 , passou a ocupar, em setembro de 1925, o logar então deixado por Amâncio dE Carvalho. A AlcÂNTARA MAchado, nos seus catorze anos de catedrático, foram escassos (bem o sabeis) os ensejos para o exercício da atividade docente. Mandatos eleitorais repetidos, comissões oficiais, a própria doença o mantiveram quasi sempre distante do convívio escolar. Contudo, sua estensa cultura na especialidade e seu renome nacional de jurista, uma e outro realçados pelos méritos de burilador primoroso do nosso idioma, conferiram-lhe, à aristocrática personalidade de intelectual, uma refulgente auréola, cuja uminosidade projetou clarões de prestígio sôbre a "sua" Faculdade de Direito, que ele amou como poucos.

Fui, durante longo tempo, detentor provisório dos encargos da cátedra que esses dois belos espíritos engrandeceram. Tornando-me hoje seu depositário efetivo, avalio a responsabilidade que para mim significa o recebimento do suntuoso legado; mas espero poder continuar a honrar, como suponho havê-lo feito até agora, o exemplo e a memória dós dois eminentes professores.

Amplia, para o meu coração, a magnitude desta cerimônia, a presença de amigos e de colegas, que me trazem o confortante testemunho do seu júbilo. Não preciso dizer-lhes como me sinto grato pela simpática demonstração, e como me desvanece e me encanta vê-los compartilhar da minha alegria.

Comparece também a honrosa representação da Faculdade de Filosofia, Ciências e Letras, instituto a que até hoje pertencí, como titular da cadeira de Biologia educacional, e que expressa, nesta solenidade, os seus sentimentos para comigo, através da palavra fraternal de Mrton da Silva RoDRIGUES, meu companheiro de todas as horas. Quero dizer 
bem alto a esses colegas a minha gratidão. Pertencí, senhores, a uma instituição universitária paulista que um cataclismo administrativo, certo dia, subverteu. Pois bem: os náufragos dessa organização, arremessados para o seio da Faculdade de Filosofia, Ciências e Letras, foram aí acolhidos como irmãos, nela encontrando um teto hospitaleiro e a mais benévola cordialidade. Ao despedir-me dos velhos companheiros do Instituto de Educação, bem como dos novos colegas da Faculdade de Filosofia - todos agora integrados numa família única - digo-lhes, de coração aberto, que me é sumamente grata a gentileza do seu gesto, e ainda uma vez lhes asseguro a firmeza e a indestrutibilidade do meu afeto.

Vejo, por fim, reunida para receber-me, a Congregação desta vetusta Faculdade, inclusive o seu eminente titular emérito, meu querido amigo e mestre, professor Francisco Morato. E pelo douto conclave se encarrega da palavra ritual de recepção o seu ilustre presidente, professor Cardozo de Melo Neto, o qual, além de diretor, presentemente se reveste das insígnias de decano desta casa; de sorte que, ao ouvir-lhe a oração generosa e acolhedora, como que percebo as vozes de um século de gerações de mestres a me darem as boas vindas.

\section{Meus senhores}

Ainda que de direito o mais novo na Congregação, posso considerar-me de fato um dos mais antigos de seus membros. Com efeito, olhando agora o brilhante cenáculo, não vejo nos seus vinte e quatro elementos efetivos senão seis que aí já estavam, quando vim para a Faculdade. Os outros ingressaram depois; e noto mesmo entre eles, desvanecido, mas levemente pungido pela melancolia, diversos antigos alunos meus.

Em princípios de 1928, acerquei-me desta Faculdade, batendo-lhe à porta, para a obtenção da livre docência, com uma dissertação de Higiene social. Desde o último ano do curso médico, sendo assistênte do Instituto de Higiene, eu me orientara para os problemas dessa categoria, e o trabalho 
que aqui apresentei não significava senão o prosseguimento da tese com a qual me havia doutorado, em 1921, perante a Faculdade de Medicina de São Paulo. Mas - fato curioso atraido para aqui principalmente pelos capítulos de Higiene social que a cadeira então comportava, eu me ví, dois anos depois, súbitamente espoliado dessa parte, quando, em 1930, a Medicina Pública dos cursos de direito se contraiu em Medicina Legal.

Todavia, não me desesperou o escamoteamento praticado pela lei. Os largos e sedutores horizontes da Medicina Jurídica haviam-me sido desvendados, no curso médico, por dois mestres de escol, que me distinguiram com a sua estima particular, e cujos nomes evoco, neste momento, sob profunda emoção e comovido respeito: Oscar Freire, para a Medicina Legal, Franco da Rocha para a Psiquiatria Forense. Demais, nos dois anos que precederam o concurso de livre docência, meu prezado companheiro e mestre Flamínio FÁVERo houve por bem abrir-me as portas do seu magnífico Instituto - hoje, o palácio brasileiro da Medicina Legal onde, como assistente extra-numerário e debaixo da prestimosa tutela de Arnaldo Amado Ferreira, me foi dado retomar e estender contactos com as práticas peculiares ̀̀ disciplina.

$\mathrm{E}$ assim, armado, municiado, confiante, procurei as trincheiras de combate, certíssimo de que a vitória seria facil.

Vitória facil! Engano d'alma lêdo e cégo.. Para demonstrar, meus senhores, quanto nesse particular eu me iludira, permiti recordar alguns quadros episódicos.

Certa manhã, nas vésperas das provas, meu excelente amigo Ernesto Leme (nessa época simples aspirante ao logar que hoje tanto dignifica), me dizia, alarmado, pelo telefone: "Os professores da Faculdade estão indignados com o senhor! O senhor vai entrar daqui a dias em concurso, e ainda não os foi visitar!"

De fato, eu ignorava essa praxe histórica, e, por não tê-la obedecido, provocara o reparo de um catedrático da 
época. A diligente amizade do meu antigo discípulo de Pirassununga fizera o resto.

Não conservo mais, meus senhores, a lembrança integral do que foi, para a minha timidez de semi-roceiro, essa longa "via crucis" pelas residências e escritórios dos dezoito mestres de dineito de 1928. Devo confessar, entretanto, que no fim da semana, ao atingir o alto do Calvário, meu optimismo um pouco petulante já se diluira como fumo ao vento. Em cada palavra, em cada gesto dos futuros juizes, o desconfiado paulista fronteiriço julgava perceber, entrando-lhe na carne, as farpas da zombaria. Numa ou noutra frase, imaginava mesmo poder decifrar a próxima sentença capital.

Pinto Ferraz, diretor de então, com aquela sua fidalguia de figura, aquelas maneiras de grão-senhor da era vitoriana, foi singelo e objetivo: "Compareça de casaca!" determinou ele. Depois, observando-me a indumentária do momento, uma suspeita atroz deve ter-lhe atravessado o cérebro, pois julgou prudente acrescentar: "Gravata branca!"

Procurei, a seguir, o boníssimo Pacheco Prates. Não garanto, mas desconfio que desta vez, por exceção, o sábio, nobre e querido velhinho usou de ironia: "Ha em sua dissertação (comentou) umas coisas de direito romano. Faz muito bem: estude essa matéria, que é interessante. $O$ senhor verá. E olhe que na sua idade eu era ainda analfabeto!"

Rafael Sampáio (o causador confesso do telefonema alarmado de ERnesto Leme) me maravilhou por mais de uma hora com o caleidoscópio inquieto dos seus paradoxos. "Precisamos (afirmou) precisamos conhecer, antes do concurso, e de viva voz, a biografia do candidato. Ou, como dizem vocês médicos, fazer-lhe a anamnése. A Faculdade é uma família, e de quem pretenda entrar para lá dever-se-ia mesmo exigir o "pedigree". Já viu as corridas da Moóca? Pois nemhum corredor inscreve sem o "pedigree". Demais (prosseguio) dar aulas constitúi apenas parte - e até parte secundarissima - da obrigação docente. Como não se tem 
por bom o sacerdote que só diz missa, também não é professor completo quem se limite a dar aulas. A atividade social representa parte integrante da docência; e a melhor ocasião de se aferir a capacidade do candidato para essa função, está na visita protocolar. Devia mesmo haver uma nota para ela. Foi por isso (concluio) foi por isso que reclamei a sua apresentação".

Quanto a mim, canhestro, gaguejante, saí dalí convencido de haver, naquela primeira prova, alcançado nota zero.

Cardozo de Melo Neto, depois de cordialissima palestra, avivada por uma dezena de anedotas acadêmicas, resumio seu plano de batalha em uma frase final, que me deixou gelado: "Para podermos ser benévolos nos concursos de catedráticos (declarou), pretendemos, nos concursos de livre docência, usar o máximo rigor".

Os que conhecem SPEncer VAmpré fácilmente imaginarão a acolhida jovial e bondosa que me proporcionou, em sua bela biblioteca, o insigne mestre de Introdução à ciência do direito. Contudo, para que o trato pessoal do anfitrião não me induzisse em ilusões, advertiu, no momento da despedida: "De uma coisa não se esqueça o meu amigo: senatores boni viri, senatus mala bestia..."

Sampáio Dória, meu chefe de outrora, meu amigo e mestre de sempre, grande responsavel por aquela aventura toda, foi cruelmente lacônico: "Ainda não acabei de ler a sua dissertação (antecipou-me desde logo) : achei por lá um galicismo tremendo, que me desorganizou o sistema nervoso". O galicismo, realmente horrivel, era o verbo "aclimatar".

Valdemar Ferreira, por fim, o último de cujo comentário me recordo, recebendo-me à rua 15 de Novembro, no amplo salão que lhe servia de escritório, prevaleceu-se da nossa vizinhança de origem e do fato de falarmos o mesmo sotaque das fraldas da Mantiqueira, para usar a franqueza não raro mordaz que o caracteriza: "Sua dissertação (disse 
ele) é excelente... é excelente como trabalho de reportagem!"

E assim, meus senhores, na cruciante espectativa de quem prevê um malôgro tão certo como é certo o nascer matutino do sol, aqui me apresentei, em novembro de 1928. Mas, com grande surpresa para mim, e maior alegria, as previsões funestas não se verificaram. Um dia, depois de atormentado pela dialética de ágeis espíritos da Congregação (três dos quais, os mais diabólicos, recentemente nos foram restituidos), depois de manipulado segundo as normas tradicionais da casa, saí da velha sala $\mathrm{n} .1$ - a câmara de torturas - desarticulado e cambaleante, para ser, no dia seguinte, proclamado vencedor...

Desde aí, meus senhores, e a despeito da rudeza da cerimônia de iniciação, tem crescido a minha amizade por esta Faculdade e pelos mestres que integram a sua corporação docente. Deles me vieram reiterados estímulos para o trabalho; com eles me habituei ao prazer de contemplar e compôr as paisagens doutrinárias das ciências da sociedade; entre eles, na média dos seus espíritos, aprendí que a suprema lição da elegância mental está no comedimento, na repugnância pelo colorido berrante ou pelo gesto espetacular. E pude ver, no exemplo vivo de cada dia, como homens de todas as crenças, das mais diversas tendências filosóficas, das mais opostas ideologias, logram descobrir aquí um terneno comum, no empenho de viver polidamente uma vida intelectual de tolerância e de cooperação. A prova melhor desta larga compreensão da harmonia social está em que entre eles encontra indulgência e perdão a minha inoperante incredulidade religiosa; e - o que é bem mais dificil, pois se trata de matéria política em uma escola de políticos certos elementos, tão brilhantes na inteligência quão recentes na composição da casa, me permitem declarar, sem reação maior que não seja a de um sorriso, a minha profunda e inabalavel fé na democracia e no voto universal.

Tudo isto, meus senhores, para os mestres da Faculdade. Que direi, entretanto, dos seus estudantes? 
Posso confessar agora que foram eles a causa de um dos maiores pavores da minha carreira de professor. Recebí, um dia, no segundo semestre de 1929, curto memorandum de Júlio Maia: Alcântara Machado se licenciara; o diretor me convocava para a substituição; a aula, na manhã seguinte, deveria versar sôbre a identificação pelos ossos.

Eu já estava calejado, senhores, no magistério e até fóra dele, para perigos graves; mas esse, de enfrentar uma turma de acadêmicos de direito (ou, melhor, duas turmas, pois justamente em 1929 o $4 .^{\circ}$ e o $5 .^{\circ}$ andavam recebendo, simultaneamente, lições de Medicina Legal) esse perigo me pareceu ultrapassar a minha temeridade. Falava-se à boca pequena (certamente para me intimidar) em "trotes" nos professores novatos, em "trotes" nos docentes não bachareis, e eu já me via escorraçado da sala, não pela porta por que entrara, mas pela janela; contundido, escoriado; com a roupa a escorrer clara de ovo. Demais, que assunto infeliz me arranjara Jú́lo Máía para uma aula inaugural: a identificação pelos ossos

Mas vim. Vim, e ainda uma vez a minha estrêla me sorriu. Os estudantes daquele ano (entre os quais um, loiro, vivo, zombeteiro, chamado Joaquim Canuto Mendes de ALMEIDA), me receberam pacíficamente, deixaram-me falar, e, com a atenção por mim habilmente desviada para três crânios que o professor Bovero me emprestara - o de um branco, o de um negro e o de um japonês - me permitiram chegasse intacto ao término da áula.

Desde aí ficamos bons amigos, os estudantes e eu. Eu, um pouco distante, rabugento, talvez excessivamente assíduo, (como me exprobou um dia um velho professor); atento demais nas horas de prova escrita, imprudente perguntador no momento do exame oral. Eles, incomparavelmente mais estudiosos do que o admite a fama, e perfeitos nas aulas. Assegura-se que quando soltos pelos pátios ou no território livre do largo São Francisco, são uns demônios, e eu o acredito. Mas na sala, salvo o caso endêmico de dois ou três dor- 
minhocos inofensivos, a preocupação de todos é ouvir, tomar notas, indagar, compreender.

Quero, por isso, neste instante tão grato para os meus sentimentos de professor, endereça $r$ daqui uma saudação muito afetuosa às diversas gerações acadêmicas que, de 1929 a 1941, passaram pelas minhas áulas.

Devo, entretanto, meus senhores, terminar esta oração, que já ultrapassou os limites marcados pelo protocolo.

Estando eu no meu trigésimo primeiro ano de magisté rio oficial, e ha treze anos já nesta Faculdade, poder-se-á pensar que a investidura de hoje significa (mais ou menos como disse, em ocasião análoga, o saudoso professor ENJoLrAS VAMpré) uma espécie de matrimônio "in extremis", efetuado à beira do leito, unicamente para regularizar a situação dos filhos já nascidos. Não, meus senhores, não penso assim. Tenho diante de mim, ainda, um largo programa a executar, na Faculdade de Direito, e sinto que pọsúo não só o desejo como também as fôrças para executá-lo. A cadeira de Medicina Legal oferece janelas amplas para o mundo biológico, psicológico e social. Por essas aberturas, rasgadas sôbre as realidades humanas, o ambiente, não raro artificial, circunscrito pelos velhos muros do direito, recebe ondas vivas de sol, que o iluminam e o aquecem. Dentro da Medicina Legal, e no simples desenvolvimento do seu programa, espero coadjuvar, com eficiência cada vez maior, o trabalho desta casa na formação cultural da mocidade; e, penso ainda cooperar com os meus doutos colegas na tarefa, já encetada, de renovação do ensino jurídico paulista. Tolhido pelas limitações naturais do meu engenho, não contribuirei, é certo, com grande coisa. Mas haverá da minha parte, como até hoje, pertinácia e continuidade. E tudo quanto fizer, fá-lo-ei com os olhos postos na grandeza secular desta Faculdade e a aspiração muito viva de que prevaleçam no Brasil a ordem jurídica e a paz" 


\section{BIBLIOGRAFIA \\ I - Sôbre Medicina Legal}

1. Crendices e superstições brasileiras ligadas à concepção, à gestação e ao prognóstico do sexo (resultados de um inquérito) - Conf. na Soc. Med. e Cirurg. de S. Paulo, 1926.

2. Crendices e superstições brasileiras ligadas ao parto e aos primeiros cuidados para com o recém-nascido (resultados de um inquérito) - Conf. na Soc. Med. e Cirurg. de S. Paulo, 1927.

3. Crendices e superstições brasileiras ligadas à escolha do nome (resultados de um inquérito) - Conf. na Soc. Educação, 1927.

4. O Exame médico pre-nupcial - tese para a livre docência, ed. “Instituto D. Ana Rosa”, São Paulo, 1927.

5. O Delito de Infeção e o Código Penal - Arq. Soc. Med. Leg. Crimin. São Paulo, vol. II, ano II, fasc. 2.', jan. 1928.

6. Direito de autópsia? - Arq. Soc. Med. Leg. Crimin. São Paulo, vol. III, ano III, fasc. $1 .^{\circ}$, aut. 1931.

7 O hiato nocivo na vida legal dos menores - Arq. Soc. Med. Leg. Crimin. São Paulo, vol. IV, ano IV, jan. - dez. 1933.

8. O Alcoolismo no Brasil-Colônia - Rev. Fac. Direito São Paulo, vol. XXX, fasc. II, abril-junho 1934.

9. Data do defloramento; carûnculas mirtiformes - Rev. Fac. Direito São Paulo, vol. XXX, fasc. III, julho-set. 1934.

10. Importância da cirurgia estética - Rev. Fac. Dir. São Paulo, vol. XXX, fasc. III, julho-set. 1934.

11. Nos domínios da superstição; mau olhado e figa - Rev. Fac. Dir. São Paulo, vol. XXXI, fasc. I, jan.-março 1935.

12. Casamento sob hipnóse - Arq. Inst. Ident. Rio, ano V, n. 12, out. 1935.

13. O espiritismo é uma religião? - Rev. Fac. Dir. São Paulo, vol. XXXIV, III, set.-dez. 1938.

14. A embriaguez no teatro de Shakespeare - Rev. Fac. Dir. São Paulo, vol. XXXV, fasc. I, jan.-abril 1939.

15. A ilegitimidade no Estado de São Paulo - Rev. Arq. Municipal, ano VI, vol. LXII, nov.-dez. 1939.

16. Paternidade - Comp. Edit. Nacional, São Paulo, 1940.

17. A perícia médico-legal no Código de Processo Civil - Conf. na Soc. Med. Leg. Crimin. São Paulo, 1940. 
18. Aspectos da nupcialidade paulista - Rev. Arq. Municipal, ano VI, vol. LXVIII, julho 1940.

19. A idade para casar - Rev. Arq. Municipal, ano VI, vol. LXVIII, julho 1940.

20. A embriaguez habitual do funcionário - Conf. na Soc. Med. Leg. Crim. São Paulo, 1940.

21. Embriaguez habitual: crime ou doença? - Rev. Penal e Penitenciária, ano I, vol. I, fasc. 1.०, 1940.

22. O programa de Medicina Legal da Faculdade de Direito (resultados de um inquérito) - Ed. Fac. Dir. São Paulo, 1940.

23. A Medicina e a aplicação da lei sôbre acidentes do trabalho Conf. na Semana de Infortunística da Soc. Med. Leg. Crim. de São Paulo, 1940, publicada na Rev. Fac. Dir. São Paulo, vol. XXXVI, fasc. I, 1941.

24. Os reveladores da mentira -- Rev. Fac. Dir. São Paulo, vol. XXXV, fasc. III, 1940.

25. A destruição dos cabelos, lesão corporal - Rev. Fac. Dir. São Paulo, vol. XXXV, fasc. III, 1940.

26. Sôbre o aguardentismo nacional - Rev. Arq. Municipal, ano VI, vol. LXXII, nov.-dez. 1940.

27 O exercício da Medicina e o novo Código Penal - Lição inaugural dos cursos de 1941, na Escola Paulista de Medicina, publicada na Revista Forense, Rio, maio de 1941.

28. Alcântara Machado e a Medicina Legal brasileira - Conf. na Soc. Med. Leg. Crimin. São Paulo, 1941, publicada nos Arq. da Policia Civil, n. 1, S. Paulo, junho 1941.

\section{II - Sôbre outras matérias}

1. O Saneamento pela Educação - Tese de doutoramento pela Faculdade de Medicina de S. Paulo, 1921.

2. Cartilha de Higiene - 1." ed., 1922; 16. ${ }^{\mathrm{a}}$ ed., 1938.

3. A alimentação na idade escolar e pre-escolar - Tese oficial para - 1. Congresso Brasileiro de Higiene, Rio, 1923 (Boletim n. 15 do Instituto de Higiene).

4. Investigações sôbre algumas medidas para a avaliação da capacidade respiratória - Conf. Sociedade de Educação, 1923 (Boletim n. 16 do Instituto de Higiene).

5. Investigações sôbre a merenda escolar — Conf. Sociedade de Educação, publicada no "Estado ıde S. Paulo", 27 de marco de 1923. 
6. As verminoses nas escolas - Conf. Sociedade de Educação, 1923.

7. A prova de Schneider nas crianças e nos ancilostomados - Investig. em colaboração com o dr. Samuel Pessoa, BrasilMédico, 1924.

8. O ensino da puericultura nas escolas - Tese para a Sociedade de Medicina e Cirurgia, 1925.

9. Formação de hábitos sadios nas crianças (contribuição da escola pública paulista) - Tese oficial para o 3. ${ }^{\circ}$ Congresso Brasileiro de Higiene, 1926.

10. Anatomia e Fisiologia humanas - 1. ${ }^{\mathrm{a}}$ ed., 1931; 6. ${ }^{\mathrm{a}}$ ed., 1941.

11. Noções de Puericultura (em colaboração com o dr. Mário Mursa) $-1 .^{\mathrm{a}}$ ed., 1927;.$^{\mathrm{a}}$ ed., 1933.

12. Assistência à criança em idade escolar - Tese oficial da Conf. Nacional de Proteção à Infancia, Rio, 1933.

13. Clínicas de Nutrição e Merendas Escolares - Idem, ibidem.

14. As clínicas de Eufrenia: sua necessidade e sua organização Idem, ibidem.

15. A Escola Pitoresca - Ed. Comp. Ed. Nacional, 1934.

16. O nosso diário alimentar (resultados de um inquérito) - Arq. Inst. Educ., 1935.

17 Novos Prédios para Grupo Escolar - Estudo técnico-administrativo (em colaboração), public. oficial, 1936.

18. Anuário do Ensino do Estado de S. Paulo - Public. oficial, 1936.

19. Os problemas da escola primária na zona rural - Boletim n. 4 da Diretoria do Ensino do Est. S. Paulo, 1936.

20. Anuário do Ensino do Estado de S. Paulo - Public. oficial, 1937.

21. Biologia educacional - Ed. Comp. Ed. Nacional, 1939.

22. Evolução histórica da ciência da nutrição - Conf. inaugural do curso de dietética promovido pela Esc. Paulista de Medicina, 1940.

23. Estatística e Biologia - Conf. no Instituto Nacional de Geogr. e Estatística, Rio, 1941. 